\title{
Biodeterioration mechanisms and kinetics of SCM and aluminate based cements and AAM in the liquid phase of anaerobic digestion
}

\author{
Marie Giroudon ${ }^{1,2}$, Matthieu Peyre Lavigne², Cédric Patapy ${ }^{1}$, and Alexandra Bertron ${ }^{1, *}$ \\ ${ }^{1}$ LMDC, Université de Toulouse, UPS, INSA Toulouse, France \\ 2 LISBP, Université de Toulouse, INSA, INRA, CNRS, Toulouse, France
}

\begin{abstract}
In biogas structures, concrete faces aggressive media during anaerobic digestion. Biological activities allow the conversion of organic matter into biogas, leading to a medium characterized by a variability of composition in time and space. In order to ensure the sustainability of this expanding industry, solutions for increasing concrete durability are needed. This study aims to analyse the deterioration mechanisms of different binders focusing on the impact of the binder nature on the medium (biochemical composition) during the digestion. Binders with favourable composition to chemically aggressive media were tested: slag cement (CEM III/B), calcium aluminate cement (CAC) and metakaolin-based alkaliactivated material (MKAA), and a reference binder: OPC (CEM I). They were exposed to three anaerobic digestion cycles in liquid phase in laboratory bioreactors. The organic acids and ammonium concentrations of the liquid phase were monitored by GC and HPIC. For OPC and slag cement pastes, the chemical and mineralogical changes were characterized by SEM/EDS and XRD. Locally, the presence of binder materials has an impact on the kinetics of the digestion reaction, and therefore on the quantities of gas produced. Ammonium concentrations were above the XA3 class range. Under the conditions explored, biodeterioration mainly led to the carbonation of cement pastes.
\end{abstract}

\section{Introduction}

Biogas is produced through a degradation process of the organic matter by microorganisms under controlled anaerobic conditions [1], [2]. The process, called anaerobic digestion, consists of consecutive degradation reactions: hydrolysis, acidogenesis, acetogenesis and methanogenesis [3]. The last step of methanogenesis leads to the production of a green energy, the biogas, mostly composed of methane $\left(\mathrm{CH}_{4}\right)$ and containing a significant amount of carbon dioxide $\left(\mathrm{CO}_{2}\right)$ and traces of some gases, such as $\mathrm{H}_{2} \mathrm{~S}$ and $\mathrm{NH}_{3}$. In some cases, digestion coproducts, such as the digestate, can be used as agricultural fertilizer.

Concrete is the most commonly used construction material for the biogas industry because of its economic interests, its airtightness and thermal properties. Moreover, its use allows to meet hygiene standards in these sectors [4]. During the digestion process, the initial inorganic and organic compounds, provided by the waste, are degraded under the effect of various metabolisms into smaller molecules. Some of these components have been identified for being particularly aggressive to concrete [5]-[8]: volatile fatty acids (VFA), ammonium and dissolved $\mathrm{CO}_{2}$, leading to concrete leaching and carbonation [7], [9], [10]. The microorganisms producing the metabolites also have an impact on concrete since they colonize their surface as a biofilm, which seems to amplify the material deterioration, in terms of kinetics and intensity [11].

These deteriorations may have serious consequences both economically and environmentally. A leakage would lead to (i) a loss on the recovered amount of gas from either loss of gas, loss of substrate or oxygen input that would inhibit the process (ii) a shutdown of the plant for repairs and (iii) pollutants spill into the nearby environment.

In order to design durable structures, normative documents classify aggressive environments for concrete. In the European standard EN 206 [11] and in the French information document FD P 18-011 [12], chemically aggressive environments are classified in three classes of increasing aggressiveness: XA1, XA2 and XA3. This classification is based on the presence and concentration of aggressive agents in the environment. In aqueous media, the following criteria are considered: the aggressive carbon dioxide concentration (aggressive $\left.\mathrm{CO}_{2}\right)$, the sulfate concentration $\left(\mathrm{SO}_{4}{ }^{2-}\right)$, the magnesium ion concentration $\left(\mathrm{Mg}^{2+}\right)$, the ammonium ion concentration $\left(\mathrm{NH}_{4}{ }^{+}\right)$, the $\mathrm{pH}$, and the water hardness. In humid environments, $\mathrm{SO}_{2}$ and $\mathrm{H}_{2} \mathrm{~S}$ gases are considered to be aggressive. However, neither document considers the specific case of the organic acids [11] [12], although the $\mathrm{pH}$ is not suitable to describe the aggressiveness of

\footnotetext{
"Corresponding author: bertron@insa-toulouse.fr
} 
some organic acids [13], [14]. The biological effect on deteriorations is not taken into account either.

In this context, the final aim of this study is to identify resistant binders to biological and chemical attacks by anaerobic digestion media. Intermediary objectives are to better characterize the digestate medium in terms of aggressive agents to concrete, and to identify deterioration mechanisms of cementitious materials as a function of the binder nature. In this view, cement paste specimens made of ordinary Portland cement (reference cement, CEM I), slag cement (CEM III/B), calcium aluminate cement (CAC) and metakaolin-based alkali-activated binder (MKAA), were immersed in inoculated cattle manure for three digestion cycles (17 weeks in total). The chemical characteristics of the liquid fraction of the digestate was monitored in terms of $\mathrm{pH}$ and VFA and ion concentrations during the anaerobic digestion process, as a function of the binder nature. The chemical and mineralogical changes of the pastes were investigated using SEM observations coupled to EDS analyses, and XRD analyses. Only CEM I and CEM III degradations are presented in this paper.

\section{Materials and methods}

\section{$2.1 \quad$ Binder materials}

CEM I 52.5R, CEM III/B 42.5 and CAC cement pastes (Calcoat RG) were made with a water/binder ratio of 0.30 . The metakaolin-based alkali-activated (MKAA) paste was made using metakaolin (Argeco), liquid sodium silicate (molar ratio $\frac{\mathrm{SiO}_{2}}{\mathrm{Na}_{2} \mathrm{O}}=1.7$ ), soda and water, meeting the following molar ratios: $\frac{\mathrm{SiO}_{2}}{\mathrm{Al}_{2} \mathrm{O}_{3}}=3.6 ; \frac{\mathrm{Na}_{2} \mathrm{O}}{\mathrm{Al}_{2} \mathrm{O}_{3}}=$ $0.9 ; \frac{\mathrm{H}_{2} \mathrm{O}}{\mathrm{Na}_{2} \mathrm{O}}=14.5$.

The paste specimens were mixed adapting the French standard NF EN 196-1 procedure for mortars [15] and cast in cylindrical molds $75 \mathrm{~mm}$ high and $25 \mathrm{~mm}$ in diameter. The pastes were removed from their molds $24 \mathrm{~h}$ and 7 days after pouring for the cementitious pastes and for MKAA pastes, respectively. Then, each specimen was packed in a plastic bag in order to perform an endothermic cure in a tempered room at $20^{\circ} \mathrm{C}$ for 28 days.

\subsection{Preparation of the laboratory reactor}

Biochemical Methane Potential reactors were used in the study. About 6 grams of cattle manure and $25 \mathrm{~mL}$ of inoculum were inserted in each reactor. The microbial inoculum was collected from an industrial biogas plant in Haute-Garonne (France). Water was added until reaching an initial volume of $800 \mathrm{~mL}$. After 7 weeks, control reactors' gas production was complete. To start a new cycle of 5 weeks, 6 grams of cattle manure were added again in the reactors, as well as distilled water in order to reach $800 \mathrm{~mL}$. The third cycle started after 5 more weeks with an addition of 8 grams of cattle manure. The bioreactors were maintained at $35^{\circ} \mathrm{C}$ in an oven during the whole experiment.

\subsection{Cement paste immersion under anaerobic digestion conditions}

The paste specimens were immersed in bioreactors immediately after the inoculation of the cattle manure. The solid/liquid ratio (cement paste surface area/total liquid volume) for each bioreactor was approximately 90 $\mathrm{cm}^{2} . \mathrm{L}^{-1}$ (whereas the in situ ratio in a standard industrial digester is approximately $4 \mathrm{~cm}^{2} . \mathrm{L}^{-1}$ [8]). It was chosen to be high in order to reproduce and emphasize local conditions, influenced by the cement paste leaching. Two bioreactors were run for each kind of material as well as two control bioreactors containing inoculated cattle manure without cement paste specimen as references. Each cycle was considered as ended when gas production in the control reactors was complete.

\subsection{Sampling and analysis}

Twice a week, gas pressure was measured with a manometer and samples of $5 \mathrm{~mL}$ of medium were collected. The $\mathrm{pH}$ of each sample was measured using a $\mathrm{pH}$-meter. The sample was then centrifuged (Eppendorf, Centrifuge 5430R) during 5 minutes $\left(4^{\circ} \mathrm{C}\right.$, RCF 7197$)$. Above a gas pressure of 0.250 bar, a few $\mathrm{mL}$ of gas were withdrawn using a syringe and then the gaseous pressure was returned back to ambient pressure.

The concentrations of some ionic species $\left(\mathrm{Cl}^{-}, \mathrm{SO}_{4}{ }^{2-}\right.$, $\mathrm{PO}_{4}{ }^{3-}, \mathrm{Na}^{+}, \mathrm{NH}_{4}^{+}, \mathrm{K}^{+}, \mathrm{Mg}^{2+}, \mathrm{Ca}^{2+}$ ) were analyzed by Ion Chromatography (Eluent flow $0.75 \mathrm{ml} / \mathrm{min}$, eluants $\mathrm{KOH}$ and MSA, Dionex Thermofisher DX320).

The concentrations of some volatile fatty acids (acetic acid, propionic acid, isobutyric acid, butyric acid, isovaleric acid, valeric acid) were evaluated. $1 \mathrm{~mL}$ of the supernatant part was sampled and mixed with $0.5 \mathrm{~mL}$ of an internal standard (solution of 2-ethyl-2-butyric acid at 1 g. $\mathrm{L}^{-1}$ in demineralized water and containing $5 \%$ orthophosphoric acid $\left.\mathrm{H}_{3} \mathrm{PO}_{4}\right)$ in order to be analyzed by Gas Chromatography (Vector gas $\mathrm{N}_{2}$, vector gas flow rate $25 \mathrm{ml} / \mathrm{min}$, Varian Chromatographic Column: CPWAX58 / FFAP, column flow rate: $8 \mathrm{~mL} / \mathrm{min}$ GC Varian SERIE 3900/430).

The composition of the gas phases $\left(\mathrm{O}_{2} / \mathrm{N}_{2}, \mathrm{H}_{2}, \mathrm{CH}_{4}\right.$ and $\mathrm{CO}_{2}$ ) was analyzed by Gas Chromatography (GC Trace 1300 Thermofisher).

\subsection{Analysis of cementitious materials}

The cement paste specimens were carefully sawn perpendicularly to their axes (i) to collect specimen slices for solid analyses on the one hand, and (ii) to preserve biofilms developed on the cement paste portions that were further re-immersed in the medium, on the other hand. The slices of cement paste intended for SEM analyses were embedded in an epoxy resin (Mecaprex Ma2+ by Presi), and dry polished using silicon carbide polishing disks (Presi) according to the procedure described in Bertron et al. [16]. The polished sections were coated with carbon and microstructural changes were characterized by Scanning Electron Microscopy (JEOL JSM-LV) 
combined with Energy Dispersive Spectrometry analyses (Brucker XFlash 6L30 SD).

The mineralogical composition changes of the specimens were characterized by X-Ray Diffraction (Brucker D8 Advance, Cu cathode, $40 \mathrm{kV}, 40 \mathrm{nA}$ ) after the second cycle, as a function of the distance to the surface in contact with the biowaste, following the method described by Bertron et al. [9]. The plane side directly exposed to the medium was first analyzed and then the sample was progressively abraded to characterize different depths of degradation.

\section{Results and discussion}

\subsection{Characteristics of the digestate as a function of the material during the anaerobic digestion}

\subsubsection{Biogas and volatile fatty acids (VFA) productions}

Figure 1 gives the total production of $\mathrm{CH}_{4}$ per gram of cattle manure introduced for each type of bioreactor. It can be noticed that the methane production of the control bioreactors decreases with cycles, meaning a decrease in the substrate's methanogenic potential over time. This is due to the evolution of the cattle manure during the storage (7 weeks +5 weeks). The first cycle shows important differences of production as a function of the type of material introduced: whereas the control bioreactors produced $292 \mathrm{NmL}$ of $\mathrm{CH}_{4}$ per gram of cattle manure, bioreactors containing MKAA produced about ten times less. The other bioreactors produced between 100 and $200 \mathrm{NmL}$ of $\mathrm{CH}_{4}$ per gram of cattle manure. During the second cycle, the bioreactors containing samples showed a methane production higher than the control ones due to the undigested cattle manure remaining in the reactors after the first cycle. The methane production of bioreactors containing MKAA remained very low but the other bioreactors containing samples showed good efficiency with productions between 200 and $300 \mathrm{NmL}$ of $\mathrm{NH}_{4}$ per gram of cattle manure. The third cycle is marked by an important methane production in the bioreactors containing MKAA.

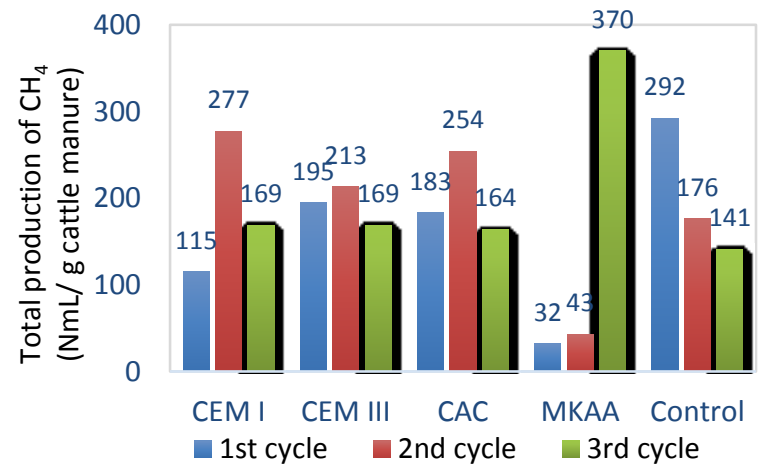

Figure 1. Total production of $\mathrm{CH}_{4}(\mathrm{NmL} / \mathrm{g}$ of cattle manure) at the end of each digestion cycle
At the end of the third cycle, for the bioreactors containing CEM I, CEM III and CAC pastes, the accumulation of produced methane was equivalent to the control bioreactors $(-6.5 \%,-5.3 \%$ and $-1.3 \%$ for CEM I, CEM III and CAC respectively compared to the control). For the MKAA bioreactors, the accumulation of produced methane indicated that all the methane potential was not expressed due the delay in the anaerobic digestion reactions.

Figure 2 and Figure 3 give the evolution of the $\mathrm{pH}$ and Figure 4 and Figure 5 give the values of the total organic acid concentrations in the biowaste liquid fraction in the bioreactors containing or not the paste specimens. Acetic acid is the predominant produced acid, far ahead of the other typical VFA metabolized by microorganisms in anaerobic digestion (propionic, butyric, isobutyric and isovaleric acids) [17], the decision was made to present the total acid concentrations for each binder material.

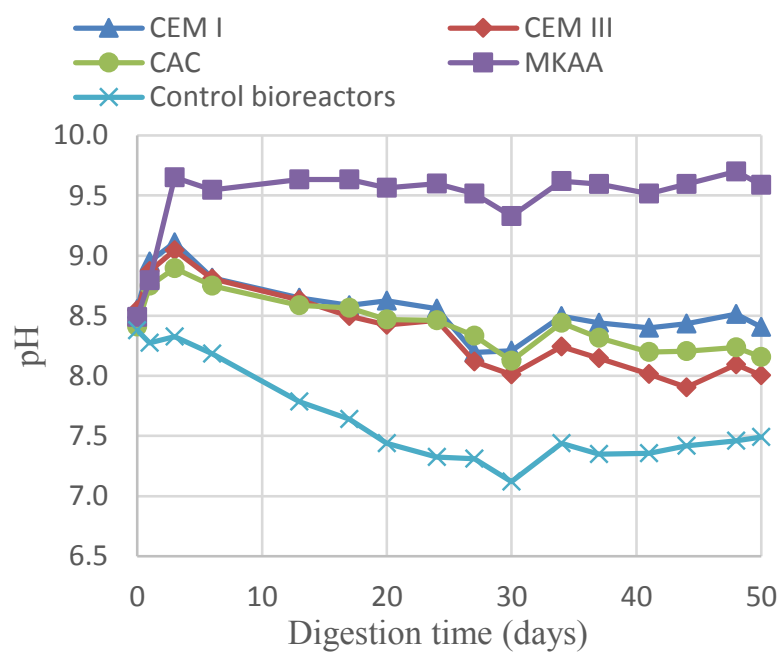

Figure 2. Evolution of the $\mathrm{pH}$ during the first cycle of anaerobic digestion in the bioreactors

Figure 2 shows that immediately after the start of the digestion cycle (day 0), the pHs were substantially identical for all bioreactors. The following measurements showed very different behaviors during the first days: the bioreactors containing material samples underwent a significant increase of $\mathrm{pH}$ up to a maximum on day 3 of about 9 for the cementitious materials (CEM I, CEM III and $\mathrm{CAC}$ ) and 9.6 for the MKAA pastes. Afterwards, the $\mathrm{pHs}$ of the bioreactors containing samples followed the same behavior as the control reactors' $\mathrm{pH}$ which decreased until day 30 , and then increased and stabilized. 3 groups stand out after the $\mathrm{pH}$ stabilization: the control bioreactors with a $\mathrm{pH}$ around 7.5 , the bioreactors containing cementitious pastes with pHs between 8 and 8.5 and the bioreactors containing MKAA pastes with a $\mathrm{pH}$ of about 9.5 .

During the second cycle, the $\mathrm{pH}$ decreased, reaching values of about 9 for the bioreactors containing MKAA and of about 7.6 in the other bioreactors, equivalent to the control. 


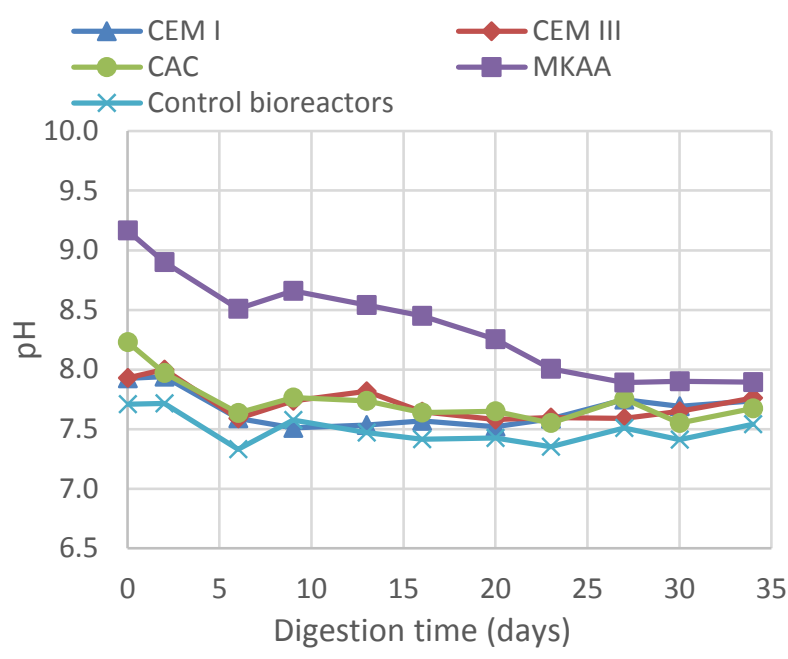

Figure 3. Evolution of the $\mathrm{pH}$ during the third cycle of anaerobic digestion in the bioreactors

The third cycle (Figure 3) presents a rapid $\mathrm{pH}$ reduction of the bioreactors containing MKAA which approach the $\mathrm{pH}$ conditions of production found in the control bioreactors, corresponding to the start of the biogas production.

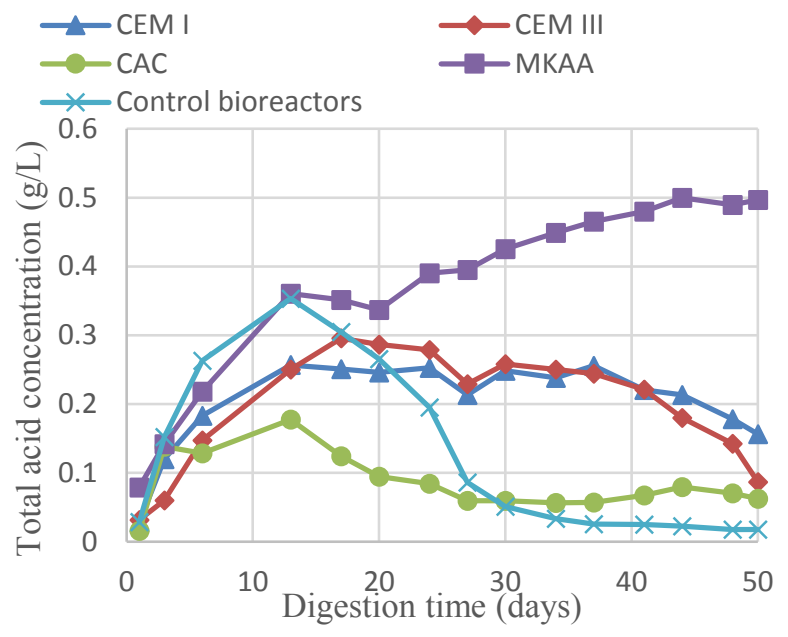

Figure 4. Concentration of total acids during the first cycle of anaerobic digestion in the bioreactors

Figure 4 shows a significant production of volatile fatty acids (VFA) at the start of the digestion. The total maximum concentration of organic acids was reached on day 13 for the control bioreactors with a value of 0.35 g.L1. The CEM I and CAC bioreactors followed the same increase and reached values 0.26 g. $\mathrm{L}^{-1}, 0.20$ g. $\mathrm{L}^{-1}$ respectively. For the CEM III specimens, the maximum concentration of VFA was reached on day 17 with a concentration of 0.30 g.L.- ${ }^{-1}$. For these bioreactors, the initial increase was followed by a slow decrease of the acid concentration, marking the consumption of the VFA and the continuation of the digestion of the substrate. The acids concentration of the MKAA bioreactors presented a different evolution and continued to increase throughout the digestive cycle, reaching a total concentration of VFA of $0.50 \mathrm{~g} . \mathrm{L}^{-1}$. These results are in accordance with the $\mathrm{pH}$ values, which are controlled by the reactivity of the binders: in the pastes, the $\mathrm{CaO}$ content leads to a buffering effect, setting a high $\mathrm{pH}$. Thus, locally, the material samples have an impact in terms of kinetics and quantity produced: the bioreactors containing CAC samples presents kinetics similar to the one of the control bioreactors, with almost two times less acid produced. The bioreactors containing CEM I and CEM III samples have a similar behavior than the control one, with a first increase in the acids concentration, but slower and less important than the one of the control bioreactors, and then a slow consumption of acids after the two first weeks. Thus, in that case, the acidogenic microbial populations overcome the material influence whereas the methanogenic microbial activities seem to be slowed down. The bioreactors containing the MKAA pastes showed the same VFA production as the control bioreactors until day 13 . Then, VFA were less consumed than in the control system and the concentration continued to increase.

During the second cycle, the total acid concentration of the bioreactors containing MKAA increased continuously reaching a concentration of 1.4 g. $\mathrm{L}^{-1}$, and no gas was produced: the local $\mathrm{pH}$ did not disturb the first step of the anaerobic digestion (acidogenesis), but stopped the methanogenesis, inducing the accumulation of VFA. In the other bioreactors, the total acid concentrations remained below 0.20 g. $\mathrm{L}^{-1}$ and biogas was produced, meaning that VFA were well consumed in order to perform the digestion of the substrate.

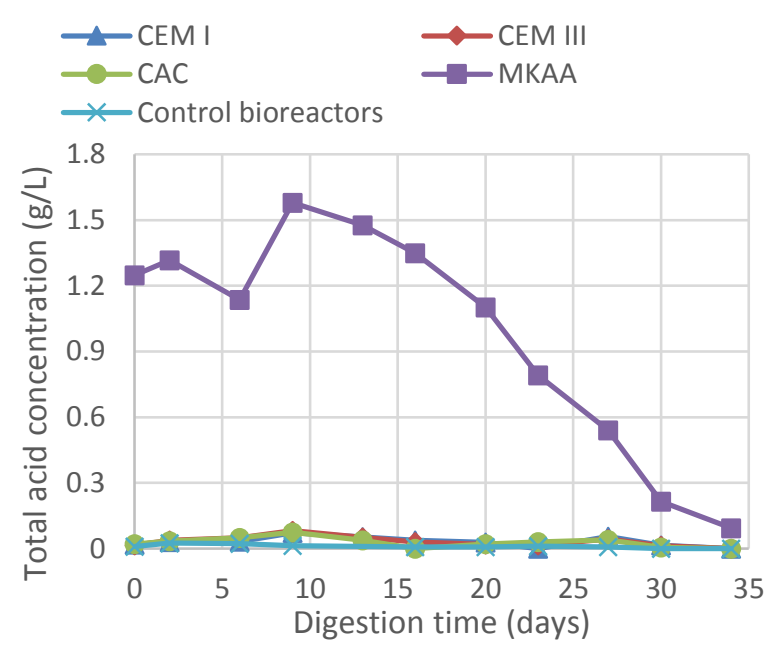

Figure 5. Concentration of total acids during the third cycle of anaerobic digestion in the bioreactors

The third cycle (Figure 5) shows the rapid consumption of the VFA in the bioreactors containing MKAA. This is in accordance with the $\mathrm{pH}$ values measured during this cycle: the decrease in $\mathrm{pH}$ in the MKAA bioreactors allowed the activity of methanogenic archaea (whose optimal pH is around 7 [18], [19]) and the consumption of the acids, leading to the production of biogas (Figure 1). 


\subsubsection{Ammonium concentration}

Figure 6 shows the evolution of the ammonium concentration during the first cycle in bioreactors with or without paste specimens. Ammonium is produced during the anaerobic digestion of organic matters due to the degradation of some proteins and urea, depending on the origin of biowaste.

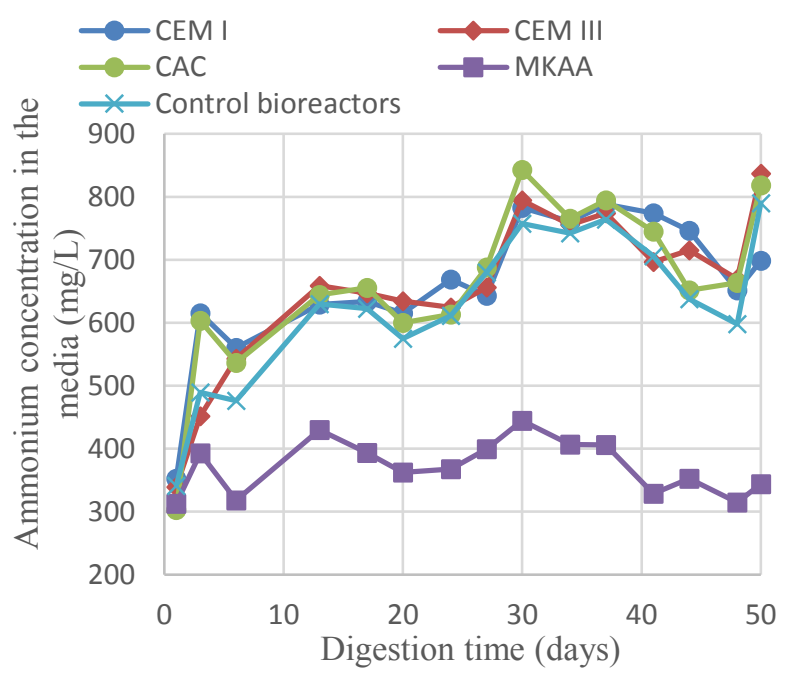

Figure 6. Evolution of the concentration of ammonium during the first cycle of anaerobic digestion of cattle manure in the bioreactors

The initial ammonium concentrations were already above the maximum range considered for chemical attacks on concrete as defined by EN NF 206 [11] and FD P18-011 [12], (XA3: 60-100 mg.L ${ }^{-1}$ ). The ammonium production increased quickly during the three first days. After 30 days of digestion, the ammonium content reached about $800 \mathrm{mg} . \mathrm{L}^{-1}$ for the bioreactors with cement paste samples (CEM I, CEM III and CAC) and for the control bioreactors, and $445 \mathrm{mg} . \mathrm{L}^{-1}$ for the bioreactors containing MKAA. These results are in accordance with previous results, illustrating the lower degradation of organic matter in the case of MKAA contact. In the bioreactors with cement pastes and in the control bioreactors, the $\mathrm{pH}$ is significantly lower than the $\mathrm{pKa}$ of the acid and conjugate base $\mathrm{NH}_{4}^{+} / \mathrm{NH}_{3}$ i.e. 9.25 (Equation 1). In these conditions, ammonium is mainly in the form of the ammonium ion. On the contrary, in the bioreactors containing the MKAA pastes, the $\mathrm{pH}$ is most of the time above 9.5. Ammonium is thus also present in the ammoniac form, a volatile component which could have passed in the gas phase without being quantified, which could explain the lowest values found in that case. The high $\mathrm{pH}$ could also have induced particular precipitation conditions of ammonium-bearing salts, where ammonium could have been consumed. Thus, the presence of material samples does not seem to influence the production of ammonium except in the case of MKAA. This is coherent with the study of Voegel et al. [7] where the evolutions of the concentration of ammonium during the anaerobic digestion of biowaste in presence and in absence of CEM I paste sample were similar. On the other hand, their results showed lower initial concentrations of ammonium
(10 mg.L-1) with a quick increase until $500 \mathrm{mg} . \mathrm{L}^{-1}$ in two weeks. After four weeks of digestion, the ammonium content of both studies reached $800 \mathrm{mg} . \mathrm{L}^{-1}$.

$$
\mathrm{NH}_{4}{ }^{+}+\mathrm{H}_{2} \mathrm{O} \rightarrow \mathrm{NH}_{3}+\mathrm{H}_{3} \mathrm{O}^{+}: \mathrm{pKa}=9.25
$$

At the beginning of the second cycle, the ammonium concentrations dropped because of the dilution effect. The values were between 600 and $700 \mathrm{mg} . \mathrm{L}^{-1}$ for all bioreactors except those containing MKAA where the value dropped at $300 \mathrm{mg}$. $\mathrm{L}^{-1}$. The values remain high during the third cycle, with concentrations between 500 and $700 \mathrm{mg} . \mathrm{L}^{-1}$ for the control bioreactors and bioreactors containing cementitious materials, and about $150 \mathrm{mg} . \mathrm{L}^{-1}$ for the bioreactors containing MKAA.

\subsection{Chemical and mineralogical changes in CEM I and CEM III pastes}

The choice have been made here to present only CEM I and CEM III degradations in order to focus on CEM III particularities. CAC and MKAA materials will be the subjects of future papers.

\subsubsection{Chemical changes}

Figure 7 shows SEM observations in BSE (BackScattered Electron) mode of polished cross sections of CEM I and CEM III specimens exposed to anaerobic digestion conditions for 7 weeks. A chemical zonation of the specimen was identified by EDS analysis. The same types of observations were made on control specimens of the same age, kept wrapped in plastic film to avoid carbonation. The typical compositions of the various zones of the CEM I paste and the CEM III, marked 1 to 4 and shown on Figure 7 are given in Table 1.

From the core of the specimen to the outer layer, the zonation of the pastes was as follow:

- Zone 1 or sound zone, showed an unaltered cement paste with white anhydrous grains of cement surrounded by grey hydrates (Portlandite ,C-S-H, AFm, Aft,...).. The chemical composition of this zone corresponded to that of the unaltered control specimen for the CEM I paste and was closed to that of an unaltered control specimen (Table 1) for the CEM III paste.

- Zone 2 was $225 \mu \mathrm{m}$-thick for the CEM I paste and 130 $\mu \mathrm{m}$-thick for the CEM III paste. It was characterized by a darker contrast of the cement paste probably due a higher porosity.

- Zone 3 was $75 \mu \mathrm{m}$-thick for the CEM I paste and 100 $\mu \mathrm{m}$-thick for the CEM III paste. For the CEM I paste, it was characterised by the almost complete dissolution of anhydrous grains. In the CEM III paste, this zone showed a significant loss of density (dark areas on the SEM picture). Low density areas were observed at concentrated locations.

- Zone 4, corresponding to the outer layer, showed a high calcium content. It was few $\mu \mathrm{m}$ thick in the CEM I paste. In the CEM III paste, the outer layer was the most degraded zone and could not be observed everywhere. 


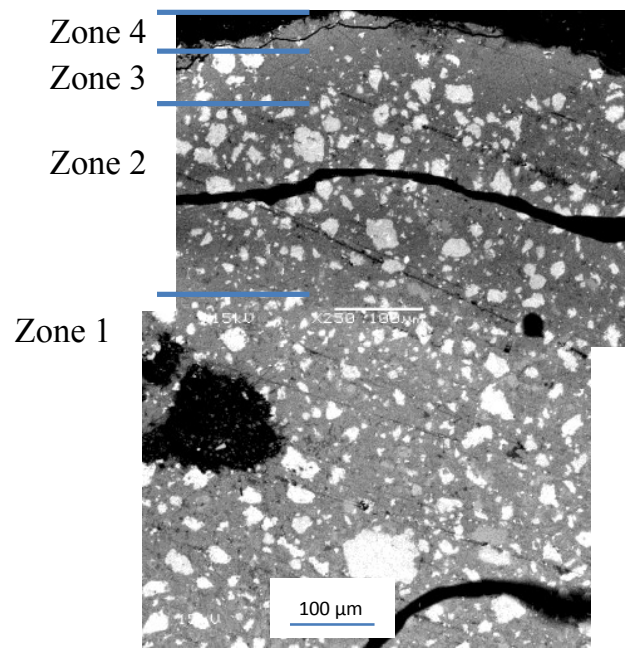

(a)

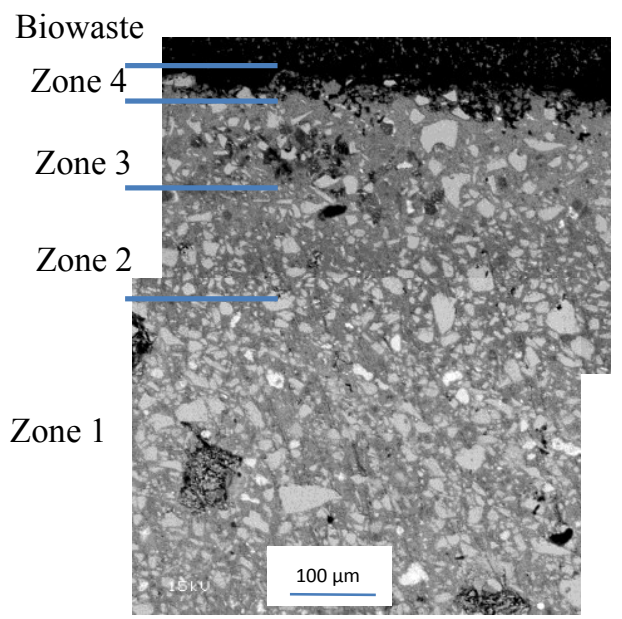

(b)

Figure 7. Observations by SEM of a polished section of (a) a CEM I cement paste and (b) a CEM III cement paste exposed to anaerobic digestion conditions for 7 weeks

Table 1. Average chemical compositions (calculated on a minimum of 5 point analysed) and standard deviations in mass percentages in the different zones defined on Figure 7 of (a) the CEM I paste and (b) the CEM III paste and in the control specimens

\begin{tabular}{|c|c|c|c|c|c|c|}
\hline & & Control specimen & Zone 1 & Zone 2 & Zone 3 & Zone 4 \\
\hline \multirow{3}{*}{ 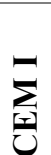 } & $\mathrm{CaO}$ & $65,17 \pm 5,57$ & $67.96 \pm 1.91$ & $69.78 \pm 9.24$ & $70.04 \pm 8.65$ & $72.43 \pm 7.66$ \\
\hline & $\mathrm{SiO}_{2}$ & $23,85 \pm 6,28$ & $22.56 \pm 1.91$ & $17.44 \pm 6.09$ & $20.58 \pm 7.45$ & $17.52 \pm 5.46$ \\
\hline & $\mathrm{Al}_{2} \mathrm{O}_{3}$ & $4,13 \pm 3,56$ & $4.18 \pm 1.36$ & $5.65 \pm 6.02$ & $4.40 \pm 1.05$ & $6.46 \pm 6.38$ \\
\hline \multirow[t]{2}{*}{ (્తి } & $\mathrm{P}_{2} \mathrm{O}_{5}$ & $0,06 \pm 0,09$ & $0.01 \pm 0.01$ & $0.01 \pm 0.03$ & $3.85 \pm 9.38$ & $0.96 \pm 1.82$ \\
\hline & $\mathrm{SO}_{3}$ & $3,50 \pm 3,27$ & $7.98 \pm 3.54$ & $4.93 \pm 3.10$ & $0.92 \pm 0.05$ & $0.55 \pm 0.32$ \\
\hline \multirow{3}{*}{$\Xi$} & $\mathrm{CaO}$ & $49.70 \pm 4.38$ & $42.00 \pm 2.15$ & $74.15 \pm 6.49$ & $54.10 \pm 13.06$ & $76.25 \pm 7.72$ \\
\hline & $\mathrm{SiO}_{2}$ & $31.38 \pm 5.56$ & $37.32 \pm 2.66$ & $15.90 \pm 5.90$ & $26.65 \pm 10.96$ & $15.47 \pm 6.14$ \\
\hline & $\mathrm{Al}_{2} \mathrm{O}_{3}$ & $8.03 \pm 1.77$ & $10.43 \pm 1.28$ & $3.78 \pm 1.13$ & $10.70 \pm 9.01$ & $3.96 \pm 1.32$ \\
\hline \multirow{2}{*}{ (2) } & $\mathrm{P}_{2} \mathrm{O}_{5}$ & $0.05 \pm 0.10$ & $0.03 \pm 0.06$ & $1.23 \pm 1.44$ & $0.51 \pm 1.26$ & $0.33 \pm 0.47$ \\
\hline & $\mathrm{SO}_{3}$ & $5.21 \pm 3.02$ & $3.68 \pm 2.77$ & $1.72 \pm 0.93$ & $2.70 \pm 3.05$ & $1.05 \pm 0,43$ \\
\hline
\end{tabular}

The total degraded layer depth was more than $300 \mu \mathrm{m}$ for the CEM I paste and was about $230 \mu \mathrm{m}$ for the CEM III paste.

Results in Table 1 show that despite the chemical conditions in the liquid phase (high concentration of organic acids and ammonium) which should have led to leaching, calcium was preserved in the specimen. The relative content of $\mathrm{CaO}$ was almost constant in the different zones in CEM I specimen. The $\mathrm{CaO}$ concentration profile was more erratic in CEM III paste: zones 2 and 4 showed high relative $\mathrm{CaO}$ contents, suggesting movement of $\mathrm{Ca}$ from some zones to others and re-precipitations. Moreover, the low density areas observed in zone 3 of CEM III specimen showed a high content of silicium (about 70\%) and a low content of calcium (about 10\%), which marked a strong decalcification.. These observations may be linked with dissolution/precipitation phenomena, which could not be fully explained with SEM/EDS analyses observations only. It was also observed enrichments of phosphorus, most likely brought by the medium, some points of zones 2 to 4 for CEM I and CEM III specimens.

These results are quite different from the SEM/EDS analyses from Voegel et al. [8], who used a more aggressive substrate: after 4 weeks of anaerobic digestion, the degraded depth was about $200 \mu \mathrm{m}$ but with a more intense degradation. The attack resulted in (i) partial decalcification and dissolution of anhydrous grains in zones 2 and 3, (ii) P-bearing precipitates identified as apatite minerals in zone 4, (iii) a nearly complete decalcification of the outer layer with a high silica content. 


\subsubsection{Mineralogical changes}

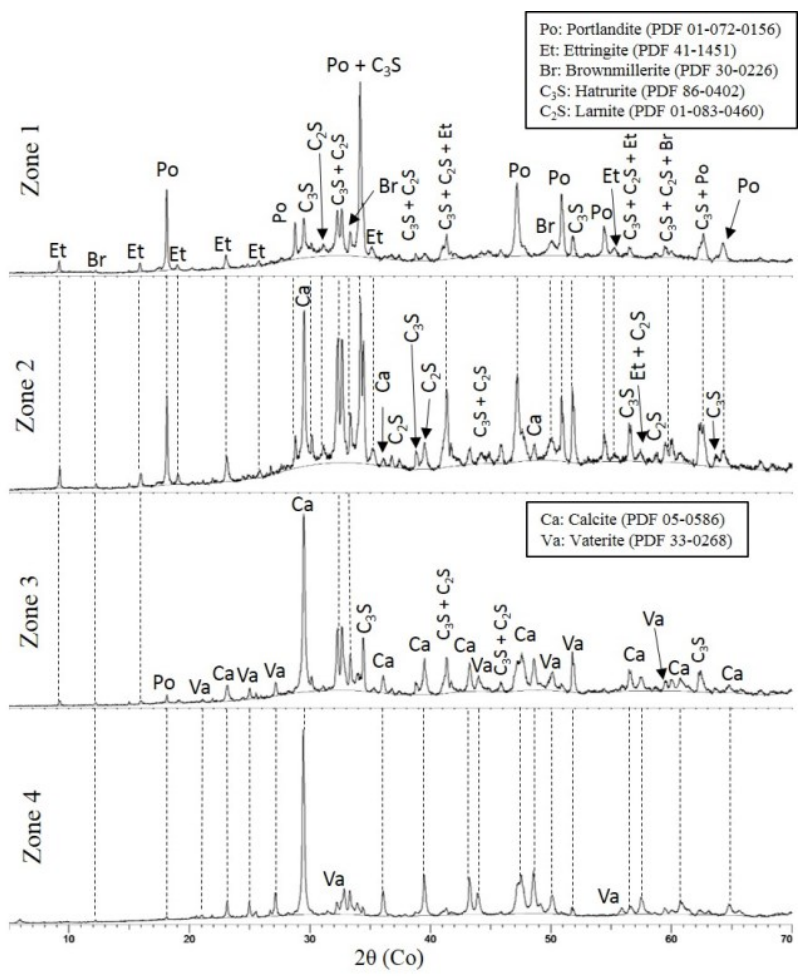

Figure 8. Mineralogical analysis by XRD of CEM I pastes exposed to anaerobic digestion conditions for two cycles

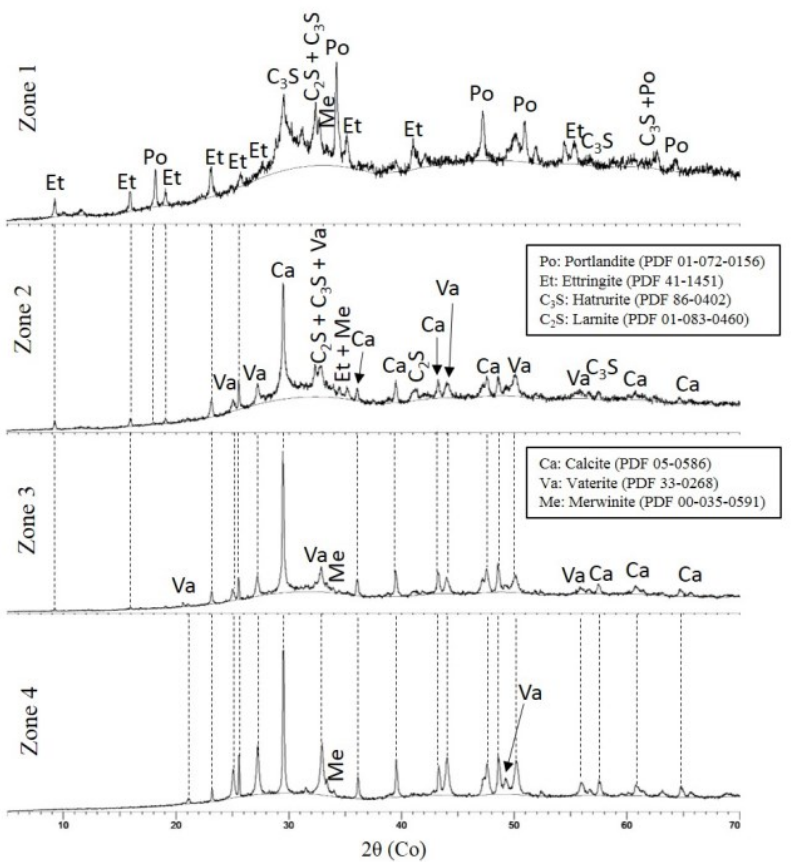

Figure 9. Mineralogical analysis by XRD of CEM III pastes exposed to anaerobic digestion conditions for two cycles

Figure 8 presents the X-Ray patterns obtained in the core (zone 1) and in the altered zones (zones 2 to 4 ) of the CEM I paste at the end of the 2 digestion cycles. A similar pattern was found for CEM III paste (Figure 9). The results showed leaching phenomena with the dissolution of the initial phases (ettringite, portlandite, brownmillerite, $\mathrm{C}_{3} \mathrm{~S}$ and $\mathrm{C}_{2} \mathrm{~S}$ ) and carbonation phenomena with the precipitation of calcium carbonates (calcite and vaterite), which is in accordance with the high contents of calcium in the outer layer of the cement paste specimens. No peaks related to P-bearing phases were observed in accordance with Voegel et al.'s results [8]. The authors supposed that an amorphous form of apatite may have precipitated in the specimens because of a recombination of leached $\mathrm{Ca}$ and $\mathrm{P}$ brought out by the digestate.

\section{Conclusion}

In this study, binder paste specimens were exposed to three anaerobic digestion cycles of cattle manure in laboratory conditions. The liquid medium was investigated in terms of $\mathrm{pH}$, acids and ammonium productions.

First, the high solid/liquid ratio enabled to exacerbate the influence of the materials' reactivity on the biological reactions, highlighting the local $\mathrm{pH}$ effect of MKAA paste on the last step of the methane production. The materials' influence seems to decrease with the advancement of the reactions, which is probably due to the progressive degradation of the material but also to the possible adaptation of the microorganisms.

The digestion process led to a production of organic acids (acetic, propionic, butyric, isobutyric and isovaleric acids) with maximal concentrations varying between 0.20 g. $\mathrm{L}^{-1}$ and 1.60 g.L. $\mathrm{L}^{-1}$ depending on the materials, due to the reversible inhibition of the methanogenic reactions in some cases (MKAA). This production of acids was accompanied by a slight acidification in the control bioreactor whereas the presence of binder pastes in the medium was found to cause the increase of the $\mathrm{pH}$. After the first increase, $\mathrm{pH}$ decreased and stabilized. In addition, ammonium was co-produced in high concentrations above the maximum range considered for chemical attacks on concrete (XA3: 60-100 mg. $\mathrm{L}^{-1}$ ), reaching 800 mg. $L^{-1}$ after 30 days.

As in Voegel et al.'s study [8], the biodeterioration was expressed by a combination of leaching and carbonation phenomena, as analyzed with SEM+EDS and XRD. The CEM III pastes have a lower degraded depth than the CEM I ones, however, at this point of the study, it is difficult to conclude on the difference in behavior between both analyzed materials.

Other cycles are necessary to confirm the results and analyses on all materials will be performed.

\section{References}

[1] S. Cole and J. R. Frank, Eds., Methane from Biomass: A Systems Approach. Springer Netherlands, 1988.

[2] P. L. McCarty, "Anaerobic Waste treatment Fundamentals," Public Works, vol. 95, no. Spt., Oct., Nov., Dec., p. 66, 1964.

[3] G. M. Evans and J. C. Furlong, Environmental Biotechnology - Theory and Application. John Wiley \& Sons, 2003. 
[4] CIMbéton, Syndicat National du Béton Prêt à l'Emploi, Syndicat National du Pompage du Béton, and Institut de l'Elevage, Ouvrages en béton pour l'exploitation agricole et les aménagements ruraux - Conception, prescription, réalisations, vol. B66. CIMbéton, 2007.

[5] A. Koenig and F. Dehn, "Biogenic acid attack on concretes in biogas plants," Biosyst. Eng., vol. 147, pp. 226-237, Jul. 2016.

[6] C. Voegel, "Impact biochimique des effluents agricoles et agroindustriels sur les structures/ouvrages en béton dans la filière de valorisation par méthanisation (ou digestion anaérobie)," Institut National Polytechnique de Toulouse (INP Toulouse), Toulouse, France, 2017.

[7] C. Voegel, A. Bertron, and B. Erable, "Mechanisms of cementitious material deterioration in biogas digester," Sci. Total Environ., vol. 571, pp. 892901, Nov. 2016.

[8] C. Voegel, A. Bertron, and B. Erable, "Biodeterioration of cementitious materials in biogas digester," Matér. Tech., vol. 103, no. 2, p. 202, 2015.

[9] A. Bertron, J. Duchesne, and G. Escadeillas, "Accelerated tests of hardened cement pastes alteration by organic acids: analysis of the $\mathrm{pH}$ effect," Cem. Concr. Res., vol. 35, no. 1, pp. 155166, Jan. 2005.

[10] C. Magniont et al., "A new test method to assess the bacterial deterioration of cementitious materials," Cem. Concr. Res., vol. 41, no. 4, pp. 429-438, Apr. 2011.

[11] AFNOR, NF EN 206. Béton - Spécification, performances, production et conformité. Paris, France, 2014.
[12] AFNOR, FD P18-011. Béton - Définition et classification des environnements chimiquement agressifs - Recommandations pour la formulation des bétons. Paris, France, 2016.

[13] A. Bertron, "Understanding interactions between cementitious materials and microorganisms: a key to sustainable and safe concrete structures in various contexts," Mater. Struct., vol. 47, no. 11, pp. 1787-1806, Nov. 2014.

[14] S. Larreur-Cayol, A. Bertron, and G. Escadeillas, "Degradation of cement-based materials by various organic acids in agro-industrial waste-waters," Cem. Concr. Res., vol. 41, no. 8, pp. 882-892, Aug. 2011.

[15] AFNOR, NF EN 196-1. Méthodes d'essais des ciments - Partie 1 : détermination des résistances. Paris, France, 2016.

[16] A. Bertron, G. Escadeillas, P. de Parseval, and J. Duchesne, "Processing of electron microprobe data from the analysis of altered cementitious materials," Cem. Concr. Res., vol. 39, no. 10, pp. 929-935, Oct. 2009.

[17] J. S. Jeris and P. L. McCarty, "The Biochemistry of Methane Fermentation Using Tracers," J. Water Pollut. Control Fed., vol. 37, no. 2, pp. 178-192, 1965.

[18] H. Huber, M. Thomm, H. König, G. Thies, and K. O. Stetter, "Methanococcus thermolithotrophicus, a novel thermophilic lithotrophic methanogen," Arch. Microbiol., vol. 132, no. 1, pp. 47-50, Jul. 1982.

[19] S. T. Yang and M. R. Okos, "Kinetic study and mathematical modeling of methanogenesis of acetate using pure cultures of methanogens," Biotechnol. Bioeng., vol. 30, no. 5, pp. 661-667, Oct. 1987. 